\title{
CHARACTERIZATION OF THE TOXICOLOGICAL EFFECTS OF AMINOCARB ON RATS: HEMATOLOGICAL, BIOCHEMICAL, AND HISTOLOGICAL ANALYSES
}

\author{
Elsa Dias, Simone Morais, Elmano Ramalheira, Maria Lourdes Pereira
}

\begin{abstract}
Aminocarb is a widely applied carbamate insecticide with action of controlling pests such as Lepidoptera and Coleoptera. In this study, subchronic effects on Wistar rats were inves-tigated using hematological, biochemical, and histological techniques. Rats were exposed orally at sublethal levels of 10, 20, or $40 \mathrm{mg} / \mathrm{kg}$ body weight (groups A, B, and C, respec-tively) for $14 \mathrm{~d}$. Hematological results revealed no statistical differences after $1 \mathrm{~d}$ of exposure but significant reduction in white blood cells detected after $7 \mathrm{~d}$ of exposure in group $\mathrm{C}$, as well as, in all treated groups after $14 \mathrm{~d}$ of exposure. Biochemical data showed a decrease of acetylcholinesterase activity in all groups after $1 \mathrm{~d}$ of exposure with a return to normal after 7 and $14 \mathrm{~d}$. Significant increase in alkaline phosphatase activity of rats exposed to aminocarb was noted after $7 \mathrm{~d}$ of treatment. The levels of triglycerides were also significantly decreased. The present investigation also showed a significant increase in content of serum urea and creatinine in animals from group A (14 d), and from groups B and C ( 7 and $14 \mathrm{~d})$. Histological results demonstrated hemorrhagic focus on hepatic and renal parenchyma in all exposed groups. Taken together, the attained results were dose dependent and indicated adverse effects of aminocarb on hepatic and renal functions, as well as on immune responsiveness at sublethal tested doses.
\end{abstract}

Carbamate compounds are used as pesticides on a large scale worldwide. Carbamate pesticides play an important role in high agriculture productivity (Dyk and Pletschke, 2011); particularly in developing countries, these pesticides are systematically and increasingly applied as prophylactic measures due to their beneficial effects on yield (Oliveira et al., 2013; Schwarzenbach et al., 2006). Carbamates include a broad spectrum of insecticides widely used as acaricides, molluscicides, nematocides, and helmithicides, which act on the central nervous system by inhibiting the enzyme acetylcholinesterase (AChE) (Ecobichon, 2001). The toxicity of these compounds, however, is not always restricted to the target pest organism but also affects mammals
(Caldas et al., 2011; Jensen, et al., 2009). Various carbamate compounds have been reported to produce biochemical changes in different animal species (Almasiova et al., 2012; AL-Shinnawy, 2008; Moser et al., 2010; Satpal and Punia, 2010). The adverse effects of these compounds were reported in both humans and animals, including on renal, hepatic, neurological, reproductive, immune, and metabolic functions (Dias et al., 2013; Yang and TiffanyCastiglioni, 2008). Inhibition of AChE leads to an accumulation of the neurotransmitter acetylcholine at the nervous terminal after acute exposure, with the potential to alter neurological development in humans (Caldas et al., 2011; Yang and Tiffany-Castiglioni, 2008). Therefore, carbamates are considered 
hazardous to human and environment health and included in the priority list released by the U.S. Environmental Protection Agency (U.S. EPA, 2012).

Aminocarb (4-dimethylamino-3methylphenyl-N-methylcarbamate; CAS 2032-59-9) is a broad-spectrum insecticide that is used extensively in forests and to treat stored grain, grass lawns, fruits, and vegetables in order to control a number of insect pests such as Lepidoptera and Coleoptera (Ni et al., 2009; Marshall et al., 1996; Moody and Franklin, 1987). It is included in the list of Chemicals of Special Concern (Pesticide Action Network [PAN] Bad Actor Pesticides; http:// www.pesticideinfo.org/Docs/ref_toxicity7.html \#BadActor). However, toxicological information of aminocarb is quite limited (Bernier et al., 1995; Chevalier et al., 1993; Marshall et al., 1996; Moody and Franklin, 1987; Szeto et al., 2008). Aminocarb insect toxicity (Marshall, et al., 1996), acute pulmonary toxicity in rats (Chevalier et al., 1993), and percutaneous absorption in rats and monkeys (Moody and Franklin, 1987) were characterized. Inhibition of brain AChE in brook trout by aminocarb and its toxic metabolites was also evaluated (Szeto et al., 2008). In addition, like other $\mathrm{N}$-methylcarbamates, this compound may generate potential carcinogen agents such as $\mathrm{N}$-nitrosocarbamates (Morais et al., 2012; Ni et al., 2009).

Considering that the undesired effects of carbamates have been recognized as a serious environmental and public health concern (Frederick, 2011; Morais et al., 2012; Ni et al., 2009; Rawn et al., 2006; Ritter et al., 2006), the aim of this study was to characterize the sublethal effects of aminocarb using in vivo assays on Wistar male rats.

\section{MATERIALS AND METHODS}

\section{Chemicals and Solutions}

Aminocarb (99.9\% purity) was purchased from Fluka (Sigma-Aldrich, Steinheim, Germany). Reagents for hematological and biochemical analysis were kindly provided by
HoribaABX, SAS (Portugal), and by Siemens Healthcare Diagnostics (Portugal), respectively. Other chemicals used in this study were of analytical grade.

\section{Animal Groups and Experimental Design}

Two-month-old male Wistar rats, purchased from Harlan (Spain), were divided into 4 groups, $\mathrm{A}, \mathrm{B}$, and $\mathrm{C}$ as exposed groups and $\mathrm{D}$ as control (each $n=5$ ), and kept at standard conditions: temperature $21 \pm 2{ }^{\circ} \mathrm{C}$, relative humidity $55 \pm 10 \%$, and 12-h light/dark cycle. Free access to food and water was provided with acclimatization for $5 \mathrm{~d}$.

Aminocarb was administered orally to groups $\mathrm{A}-\mathrm{C}$ at doses of 10,20 , or $40 \mathrm{mg} / \mathrm{kg}$ body weight, respectively. After 1,7 , or $14 \mathrm{~d}$ of exposure to the insecticide, blood samples were collected from the tail vein from all animals for hematological and biochemical analyses. Body weight and signs of toxicity were monitored. After $14 \mathrm{~d}$, animals were anesthetized and sacrificed. Liver and kidney were removed for histological analysis. Organs weight was also recorded. All animal procedures were performed according to ethical national guidelines for animal experimentation.

\section{Hematological and Biochemical Analyses}

Blood samples were collected into ethylenediamine tetracetic acid (EDTA)coated sterile tubes for hemogram analysis. The following hematological determinations were performed: red and white blood corpuscles (RBC, WBC), mean cell volume and corpuscular hemoglobin $(\mathrm{MCV}, \mathrm{MCH})$, platelet counts (PLT), hemoglobin ( $\mathrm{Hb})$, and hematocrit (HCT), using an automatic hematological assay analyzer (ABX Petra DX120, HoribaABX, SAS Portugal).

For biochemical analysis, samples were centrifuged at $2000 \times \mathrm{g}$ for $10 \mathrm{~min}$ and supernatant was analyzer by a Dimension RXL Max Integrated Chemistry System (Siemens, Portugal). The following biochemical parameters were quantified: total cholesterol (TChol), triglycerides (Tg), total protein (TP), alanine 
aminotransferase (ALT), aspartate aminotransferase (AST), urea (Ur), creatinine $(\mathrm{Cr})$, alkaline phosphatase (ALP), and acetylcholinesterase (AChE).

\section{Histological Analysis}

Pieces of liver and kidney from all groups were immersed in Bouin's solution, dehydrated in graded ethanol series, embedded in paraffin wax, and sectioned (5-7 $\mu \mathrm{m}$ thick) with a microtome (Leitz model 1512). Sections stained with hematoxylin and eosin were observed and photographed using a digital camera (Olympus Camedia C-5060) coupled to a microscope (Olympus BX41, Tokyo, Japan).

\section{Statistical Analysis}

Data were expressed as mean \pm standard deviation. One-way analysis of variance (ANOVA) was used to compare differences between control and treated groups. Values of $p<.05$ were considered significant.

\section{RESULTS}

\section{Clinical Signs and Body and Organ Weight Changes}

In the present study all animals survived until the end of the experiment. Although no apparent signs of toxicity were noted, a decrease in the activity of the group exposed to the highest dose (group C) was observed. A decrease in body weights after $1 \mathrm{~d}$ of insecticide administration was noted. In addition, body weight gain of exposed groups revealed a diminished rise throughout the entire duration compared to the control. The highest effects were detected after $7 \mathrm{~d}$ of insecticide administration (Figure 1). Organs weight did not reveal statistically significant differences.

\section{Hematological and Biochemical Analyses}

Hematological results revealed no statistical differences between all treated groups after $1 \mathrm{~d}$ of exposure. After $7 \mathrm{~d}$ of exposure, total WBC decreased significantly in group $C$ with

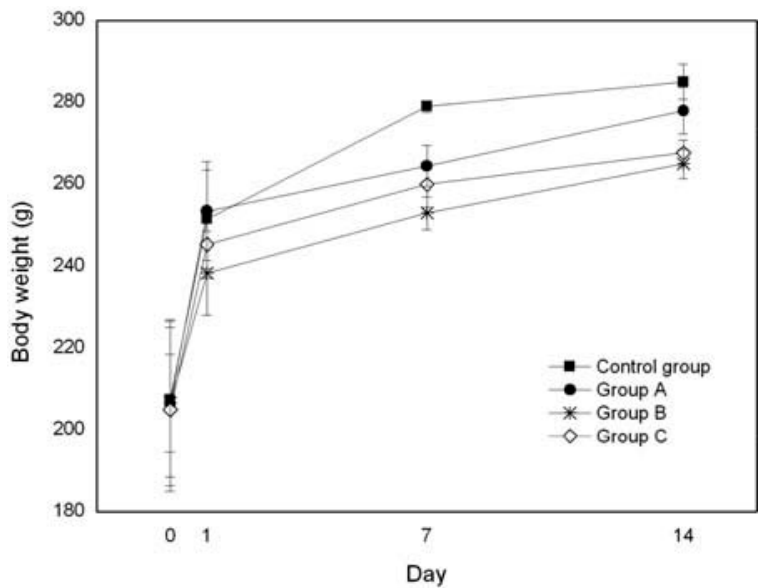

FIGURE 1. Body weight values of the tested groups of rats during the study. Vertical bars represent the standard deviation.

a decrease of neutrophils and monocytes and high levels of lymphocytes. The same pattern was observed after $14 \mathrm{~d}$ in all exposed groups. The remaining parameters did not reveal statistically significant changes (Table 1).

The biochemical results in blood samples from aminocarb exposed groups and controls during 1, 7, and $14 \mathrm{~d}$ are presented in Table 2. After $1 \mathrm{~d}$ of exposure, the biochemical parameters exhibited a significant reduction in AChE activity in all groups but normal values returned after 7 and $14 \mathrm{~d}$ of exposure. After $7 \mathrm{~d}$, ALP increased significantly in all exposed groups; $U r$ and $\mathrm{Cr}$ showed higher values in groups $\mathrm{B}$ and $\mathrm{C}$; and Tg decreased in all groups. After $14 \mathrm{~d}$ of treatment, ALP increased in group C; Ur and $\mathrm{Cr}$ rose in all exposed groups; and $\mathrm{Tg}$ fell in group $\mathrm{C}$.

\section{Histological Analysis}

Histological studies demonstrated organ damage in all aminocarb-exposed groups compared to controls with pronounced changes in group $\mathrm{C}$ after $14 \mathrm{~d}$ of exposure (Figures 2 and 3). Degenerative alterations in hepatic sections with accumulation of hepatocytes with reduced volume in group B (Figure 2a) and hemorrhagic foci and diffuse vacuolation in group C (Figure $2 b$ ) were also detected. Renal sections revealed disorganization within cortical area, including some hemorrhagic foci in 
TABLE 1. Hematological Parameters on Blood Samples From Aminocarb-Exposed Groups (10, 20, and 40 mg/kg Body Weight for Group A, B, and C, Respectively) and Controls During 1, 7, and $14 \mathrm{~d}$

\begin{tabular}{|c|c|c|c|c|}
\hline Parameter & Group & Day 1 & Day 7 & Day 14 \\
\hline \multirow[t]{4}{*}{ White blood cells $\left(10^{6} / \mathrm{mm}^{3}\right)$} & Control & $11.6 \pm 1.5$ & $11.3 \pm 0.4$ & $10.5 \pm 0.9$ \\
\hline & A & $11.4 \pm 0.8$ & $10.1 \pm 0.2$ & $6.3 \pm 1.0^{*}$ \\
\hline & $\mathrm{B}$ & $11.9 \pm 1.8$ & $11.4 \pm 0.8$ & $6.9 \pm 1.3^{*}$ \\
\hline & $\mathrm{C}$ & $11.3 \pm 0.1$ & $7.2 \pm 0.5^{*}$ & $5.9 \pm 0.3^{*}$ \\
\hline \multirow[t]{4}{*}{ Red blood cells $\left(10^{6} / \mathrm{mm}^{3}\right)$} & Control & $7.9 \pm 0.2$ & $7.8 \pm 0.1$ & $8.7 \pm 0.2$ \\
\hline & A & $7.8 \pm 0.4$ & $7.7 \pm 0.6$ & $7.8 \pm 0.5$ \\
\hline & $\mathrm{B}$ & $7.7 \pm 0.3$ & $7.7 \pm 0.4$ & $8.5 \pm 0.05$ \\
\hline & $\mathrm{C}$ & $7.9 \pm 0.1$ & $7.8 \pm 0.1$ & $8.4 \pm 0.2$ \\
\hline \multirow[t]{4}{*}{ Hemoglobin $(\mathrm{g} / \mathrm{dl})$} & Control & $15.3 \pm 0.8$ & $15.1 \pm 0.4$ & $15.7 \pm 0.6$ \\
\hline & A & $14.8 \pm 0.4$ & $15.3 \pm 0.8$ & $16.1 \pm 0.4$ \\
\hline & $\mathrm{B}$ & $15.2 \pm 0.3$ & $14.7 \pm 0.8$ & $16.6 \pm 0.1$ \\
\hline & $\mathrm{C}$ & $15.4 \pm 0.2$ & $15.2 \pm 0.2$ & $16.4 \pm 0.7$ \\
\hline \multirow[t]{4}{*}{ Hematocrit (\%) } & Control & $47.1 \pm 0.6$ & $45.3 \pm 0.2$ & $46.0 \pm 0.7$ \\
\hline & A & $45.0 \pm 1.7$ & $46.0 \pm 0.1$ & $46.0 \pm 0.8$ \\
\hline & B & $44.8 \pm 1.9$ & $43.4 \pm 0.5$ & $48.8 \pm 0.3$ \\
\hline & C & $46.2 \pm 0.9$ & $46.1 \pm 0.7$ & $46.6 \pm 2.0$ \\
\hline \multirow[t]{4}{*}{ Mean cell volume $\left(\mu \mathrm{m}^{3}\right)$} & Control & $58.3 \pm 0.9$ & $58.2 \pm 0.4$ & $55.0 \pm 0.7$ \\
\hline & A & $57.5 \pm 0.5$ & $56.1 \pm 0.7$ & $54.0 \pm 0.5$ \\
\hline & $\mathrm{B}$ & $58.5 \pm 0.5$ & $57.1 \pm 0.3$ & $57.5 \pm 0.5$ \\
\hline & $\mathrm{C}$ & $59.0 \pm 0.4$ & $56 \pm 0.8$ & $55.0 \pm 1.0$ \\
\hline \multirow[t]{4}{*}{ Mean corpuscular hemoglobin (pg) } & Control & $19.2 \pm 0.6$ & $19.4 \pm 0.3$ & $18.75 \pm 0.4$ \\
\hline & A & $18.9 \pm 0.5$ & $18.4 \pm 0.8$ & $19.4 \pm 0.3$ \\
\hline & $\mathrm{B}$ & $19.8 \pm 0.1$ & $19.2 \pm 0.2$ & $19.5 \pm 0.3$ \\
\hline & $\mathrm{C}$ & $19.4 \pm 0.1$ & $19.3 \pm 0.5$ & $19.4 \pm 0.4$ \\
\hline \multirow{4}{*}{ Platelets $\left(10^{3} / \mathrm{mm}^{3}\right)$} & Control & $664 \pm 60$ & $540 \pm 82$ & $706 \pm 42$ \\
\hline & A & $622 \pm 51$ & $710 \pm 20$ & $736 \pm 17$ \\
\hline & $\mathrm{B}$ & $531 \pm 23$ & $632 \pm 34$ & $734 \pm 136$ \\
\hline & $\mathrm{C}$ & $468 \pm 72$ & $541 \pm 31$ & $599 \pm 60$ \\
\hline
\end{tabular}

*Values statistically different at $p<.05$.

the exposed groups being more prominent in group C (Figures $3 \mathrm{a}$ and $3 \mathrm{~b}$ ).

\section{DISCUSSION}

The effects observed in body weights may probably be attributed due to loss of appetite, less food intake, and/or metabolic disturbance produced by aminocarb exposure. However in a previous study, no body weight changes were reported for another carbamate, thiodicarb (Dias et al., 2013).

Several hematological parameters were used as important biomarkers for detection of adverse effects of the insecticide. The significant reduction in WBC indicates relevant immunological effects at $40 \mathrm{mg} / \mathrm{kg}$ body weight tested dose after $7 \mathrm{~d}$ of treatment and at all tested concentrations of aminocarb after $14 \mathrm{~d}$ of exposure. These results are in accordance with Celik and Zusek (2008), which characterized the hematological effects of methyl parathion in rats. The results of the present study suggest a reduction in immune responsiveness in exposed animals.

Biochemical parameters were examined to evaluate mainly hepatic and renal functions as well as inhibition of the $A C h E$, since it is known that carbamates block this enzyme (Jensen et al., 2009). The quantification of hepatic enzymes such as ALT, AST, and ALP in blood samples revealed marked effects on ALP activity of rats exposed to aminocarb indicating hepatic disturbance after $7 \mathrm{~d}$ of treatment. Hepatic damage was also associated with significant fall in levels of triglycerides. The present investigation also showed a significant increase in content of serum urea and creatinine in animals from group A (14 d) and groups B and $C$ ( 7 and $14 \mathrm{~d}$ ), suggesting renal injury. The results were dose dependent and indicated 
TABLE 2. Biochemical Parameters on Blood Samples From Aminocarb-Exposed Groups (10, 20, and 40 mg/kg/body weight for Group A, B, and C, Respectively) and Control Group During 1, 7, and $14 \mathrm{~d}$

\begin{tabular}{|c|c|c|c|c|}
\hline Parameter & Group & Day 1 & Day 7 & Day 14 \\
\hline \multirow[t]{4}{*}{ Acetylcholinesterase (mg/dl) } & Control & $1.2 \pm 0.1$ & $1.1 \pm 0.1$ & $1.0 \pm 0.3$ \\
\hline & A & $0.9 \pm 0.1^{*}$ & $0.9 \pm 0.1$ & $1.0 \pm 0.1$ \\
\hline & B & $0.8 \pm 0.2^{*}$ & $1.0 \pm 0.2$ & $0.9 \pm 0.1$ \\
\hline & C & $0.8 \pm 0.1^{*}$ & $0.9 \pm 0.2$ & $0.9 \pm 0.2$ \\
\hline \multirow[t]{4}{*}{ Alanine aminotransferase (U/L) } & Control & $68 \pm 10$ & $63 \pm 9$ & $69 \pm 3$ \\
\hline & A & $72 \pm 11$ & $62 \pm 10$ & $54 \pm 12$ \\
\hline & $\mathrm{B}$ & $91 \pm 7$ & $68 \pm 10$ & $61 \pm 11$ \\
\hline & $\mathrm{C}$ & $99 \pm 10$ & $71 \pm 13$ & $78 \pm 3$ \\
\hline \multirow[t]{4}{*}{ Alanine aminotransferase $(\mathrm{U} / \mathrm{L})$} & Control & $104 \pm 20$ & $123 \pm 2$ & $102 \pm 3$ \\
\hline & A & $101 \pm 18$ & $80 \pm 20$ & $92 \pm 16$ \\
\hline & B & $88 \pm 25$ & $102 \pm 11$ & $93 \pm 7$ \\
\hline & $\mathrm{C}$ & $72 \pm 28$ & $99 \pm 8$ & $101 \pm 2$ \\
\hline \multirow[t]{4}{*}{ Alkaline phosphatase (U/L) } & Control & $16 \pm 3$ & $14 \pm 2$ & $18 \pm 2$ \\
\hline & A & $20 \pm 5$ & $28 \pm 3^{*}$ & $22 \pm 8$ \\
\hline & B & $19 \pm 8$ & $38 \pm 4^{*}$ & $20 \pm 3$ \\
\hline & $\mathrm{C}$ & $23 \pm 5$ & $39 \pm 3^{*}$ & $42 \pm 4^{*}$ \\
\hline \multirow[t]{4}{*}{ Creatinine (mg/dl) } & Control & $0.50 \pm 0.06$ & $0.50 \pm 0.05$ & $0.60 \pm 0.02$ \\
\hline & A & $0.60 \pm 0.04$ & $0.70 \pm 0.02$ & $0.90 \pm 0.09^{*}$ \\
\hline & $\mathrm{B}$ & $0.60 \pm 0.01$ & $1.00 \pm 0.08^{*}$ & $1.10 \pm 0.09^{*}$ \\
\hline & $\mathrm{C}$ & $0.70 \pm 0.02$ & $1.10 \pm 0.05^{*}$ & $1.20 \pm 0.05^{*}$ \\
\hline \multirow[t]{4}{*}{ Urea (mg/dl) } & Control & $26 \pm 2$ & $20 \pm 2$ & $28 \pm 9$ \\
\hline & A & $28 \pm 3$ & $31 \pm 3$ & $42 \pm 5^{*}$ \\
\hline & B & $33 \pm 9$ & $44 \pm 8^{*}$ & $47 \pm 5^{*}$ \\
\hline & $\mathrm{C}$ & $34 \pm 10$ & $43 \pm 4^{*}$ & $56 \pm 4^{*}$ \\
\hline \multirow[t]{4}{*}{ Total cholesterol (mg/dl) } & Control & $80 \pm 16$ & $124 \pm 11$ & $112 \pm 20$ \\
\hline & A & $92 \pm 5$ & $96 \pm 9$ & $123 \pm 16$ \\
\hline & B & $58 \pm 22$ & $95 \pm 3$ & $90 \pm 12$ \\
\hline & $\mathrm{C}$ & $88 \pm 16$ & $117 \pm 21$ & $84 \pm 8$ \\
\hline \multirow[t]{4}{*}{ Triglycerides (mg/dl) } & Control & $121 \pm 6$ & $136 \pm 5$ & $114 \pm 5$ \\
\hline & A & $130 \pm 17$ & $72 \pm 8^{*}$ & $88 \pm 8$ \\
\hline & B & $114 \pm 11$ & $83 \pm 6^{*}$ & $93 \pm 4$ \\
\hline & $\mathrm{C}$ & $98 \pm 10$ & $77 \pm 9^{*}$ & $62 \pm 7^{*}$ \\
\hline \multirow[t]{4}{*}{ Total proteins (g/dl) } & Control & $6.4 \pm 0.2$ & $7.4 \pm 0.5$ & $7.1 \pm 0.8$ \\
\hline & A & $6.5 \pm 0.2$ & $7.5 \pm 0.2$ & $8.0 \pm 0.2$ \\
\hline & B & $6.1 \pm 0.3$ & $9.0 \pm 0.8$ & $7.2 \pm 0.3$ \\
\hline & $\mathrm{C}$ & $8.2 \pm 0.2$ & $9.8 \pm 0.1$ & $7.1 \pm 0.6$ \\
\hline
\end{tabular}

*Values statistically different at $p<.05$
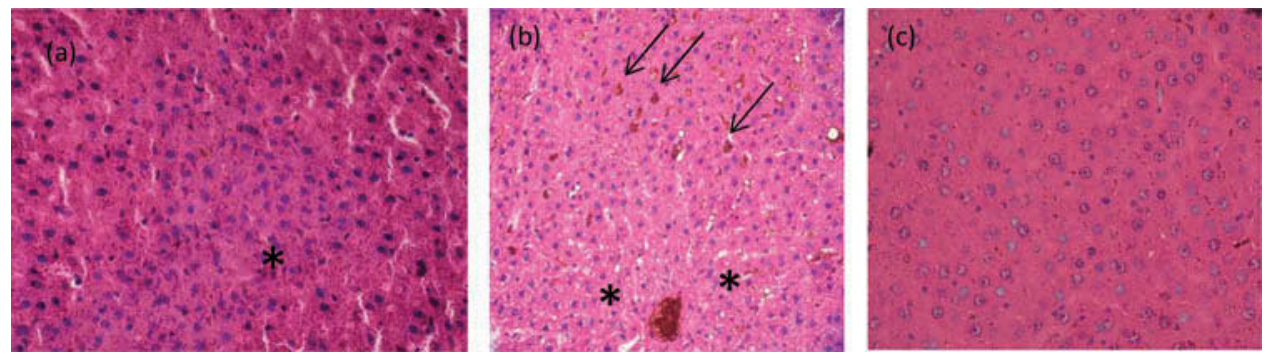

FIGURE 2. Histological section of liver of tested groups after $14 \mathrm{~d}$ : (a) group B (20 mg/kg body weight) where a massive group of hepatocytes with reduced volume $\left(^{*}\right)$ is displayed; (b) group C (40 mg/kg body weight) evidences hemorrhagic focus (arrows) and diffuse vacuolation of the tissue $\left(^{*}\right)$; (c) control group showing normal features; hematoxylin and eosin (H\&E) stain; $\times 400$.

adverse effects of aminocarb on hepatic and renal functions at the sublethal doses tested and are in agreement with previous studies conducted with other pesticides from the same class (Celik and Zusek, 2008; Al-Shinnawy, 2008; Chevalier et al., 1993). Further, a marked 

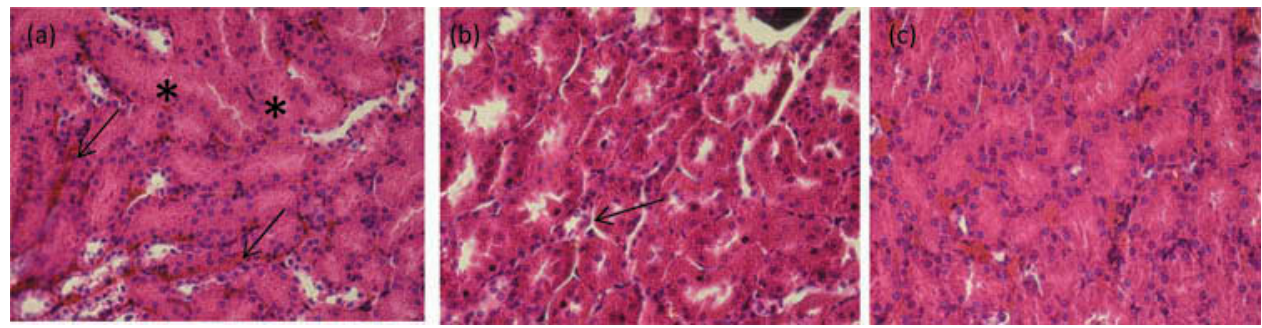

FIGURE 3. Histological section of kidney of tested groups after $14 \mathrm{~d}$ : (a) group A (10 mg/kg body weight) shows some hemorrhagic foci (arrows), and blocked renal tubules $\left(^{*}\right)$; (b) group C (40 mg/kg body weight) displays some distorted renal tubules (arrows); (c) control group showing normal features; hematoxylin and eosin $(\mathrm{H} \& \mathrm{E})$ stain; $\times 400$.

decrease in activity of AChE was noted $1 \mathrm{~d}$ after administration of aminocarb, confirming the neurotoxicity of this insecticide. These results are also in accordance with those reported for chronic exposure to other anticholinesterase acting pesticides (Wang et al., 2011).

Histopathological data of liver and kidney support the observed hematological and biochemical results. Histopatological lesions produced by aminocarb were clearly seen in all groups in a dose-dependent manner. In fact, several degenerative changes in both liver and kidney of thiodicarb exposed rats were also previously reported (Dias et al., 2013), confirming the toxicity of carbamates on these relevant organs.

In conclusion, administration of sublethal doses of aminocarb resulted in marked changes in several relevant hematological, biochemical, and histological parameters. The applied integrated approach was valuable for the assessment of insecticidal effects on liver and kidney functions. This study indicates potential hazards to wildlife and human health due to aminocarb insecticide residues exposure. Future studies will be conducted in order to obtain more insights on other relevant organs and systems to attain a holistic view.

\section{ACKNOWLEDGMENTS}

The authors are thankful to CICECO-(FCT PEst-C/CTM/LA0011/2013). Siemens Healthcare Diagnostics (Portugal) is also acknowledged.

\section{REFERENCES}

Almasiova, V., Holovska, K., Tarabova, L., Cigankova, V., Lukacinova, A., and Nistiar, F. 2012. Structural and ultrastructural study of the rabbit testes exposed to carbamate insecticide. J. Environ. Sci. Health A 47: 1319-1328.

Al-Shinnawy, M. S. A. 2008. Vitamin "C" as ameliorative agent against thiodicarb toxicated male albino rats (Rattus norvegicus). Egypt. Acad. J. Biol. Sci. 1: 177-187.

Bernier, J., Girard, D., Krzystyniak, K., Chevalier, G., Trottier, B., Nadeau, D., Rola-Pleszczynski, M., and Fournier, M. 1995. Immunotoxicity of aminocarb III. Exposure route-dependent immunomodulation by aminocarb in mice. Toxicology 99: 135-146.

Caldas, E. D., Souza, M. V., and Jardim, A. N. O. 2011. Dietary risk assessment of organophosphorus and dithiocarbamate pesticides in a total diet study at a Brazilian university restaurant. Food Addit. Contam. A 20: 71-79.

Celik, I., and Suzek, H. 2008. The hematological effects of methyl parathion in rats. J. Hazard. Mater. 153: 1117-1121.

Chevalier, G., Boudreau, J., Vicent, R., Nadeau, D., Lapare, S., Fournier, M., Krzystyniak, K., and Trottier, B. 1993. Acute pulmonary toxicity of aerosolized oil based aminocarb insecticide early responses of the pulmonary surfactant. Inhal. Toxicol. 5: 55-75.

Dias, E., Gomes, M., Domingues, C., Ramalheira, E., Morais, S., and Pereira, M. L. 2013. Subacute effects of the thiodicarb 
pesticide on target organs of male Wistar rats: Biochemical, histological and flow cytometry studies. J. Toxicol. Environ. Health A 76: 533-539.

Dyk, J. S. V., and Pletschke, B. 2011. Review on the use of enzymes for the detection of organochlorine, organophosphate and carbamate pesticides in the environment. Chemosphere 82: 291-307.

Ecobichon, D. J. 2001. Carbamate insecticides. San Diego, CA: Academic Press.

Frederick, M. F. 2011. Pesticide toxicity profile: Carbamate pesticides. Institute of Food and Agricultural Sciences (IFAS), University of Florida, Gainesville, PI-51: 1-4.

Jensen, B. H., Petersen, A., and Christensen, T. 2009. Probabilistic assessment of the cumulative dietary acute exposure of the population of Denmark to organophosphorus and carbamate pesticides. Food Addit. Contam. 26: 1038-1048.

Marshall, W.D., Yule, W. N., and Ecobichon, D. J. 1996. Synthesis, relative insect toxicity, and anticholinesterase activity of aminocarb transformation products. Arch. Environ. Contam. Toxicol. 15: 385-392.

Moody, R. P., and Franklin, C. A. 1987. Percutaneous absorption of the insecticides fenitrothion and aminocarb in rats and monkeys. J. Toxicol. Environ. Health 20: 209-218.

Morais, S., Dias, E., and Pereira, M. L. 2012. Carbamates: Human exposure and health effects. In The impact of pesticides, ed. M. Jokanović. Cheyenne, WY: Academic Press, 21-38.

Moser, V. S., Katherine, L. M., Phillips, P. M., and Lowit, A. B. 2010. Time-course, doseresponse, and age comparative sensitivity of $\mathrm{N}$-methyl carbamates in rats. Toxicol. Sci. 114: 113-123.

Ni, Y., Xiao, W., and Kokot, S. 2009. Application of chemometrics methods for the simultaneous kinetic spectrophtometric determination of aminocarb and carbaryl in vegetable and water samples. J. Hazard. Mater. 168: 1239-1245.

Oliveira, T. M. B. F., Barroso, M. F., Morais, S., Araújo, M., Freire, C., Lima-Neto, P.,
Correia, A. N., Oliveira, M. B. P. P., and Delerue-Matos, C. 2013. Laccase-Prussian blue film-graphene doped carbon paste modified electrode for carbamate pesticides quantification. Biosens. Bioelectron. 47: 292-299.

Rawn, D. F. K., Roscoe, V., Trelka R., Hanson, C., Krakalovich, T., and Dabeka, R. W. 2006. N-Methyl carbamate pesticide residues in conventional and organic infant foods available on the Canadian retail market, 2001-03. Food Addit. Contam. 23: 651-659.

Ritter, L., Goushleff, N.C.I., Arbuckle, T., Cole, D., and Raizenne, M. 2006. Addressing the linkage between exposure to pesticides and human health effects-research trends and priorities for research. J. Toxicol. Environ. Health B 9:441-456.

Satpal, J. S. K., and Punia, J. S. 2010. Studies on biochemical changes in subacute thiodicarb toxicity in rats. Toxicol. Int. 17: 30-32.

Schwarzenbach, R.P., Escher, B.I., Fenner, K., Hofstetter, T. B., Johnson, C. A., von Gunten, U., and Wehrli, B. 2006. The challenge of micropollutants in aquatic systems. Science 313: 1072-1077.

Szeto, S. Y., Sundaram, K. M. S., and Feng, J. 2008. Inhibition of brain ache in brook trout by aminocarb and its toxic metabolites. J. Environ. Sci. Health B Pestic. Food Contam. Agric Wastes 20: 559-575.

U.S. Environmental Protection Agency. 2012. National survey of pesticides in drinking water wells, Phase II report. EPA 570/891-020. Springfield, VA: National Technical Information Service.

Wang, H., Liang, Y., Zhang, Q., Long, D., Li, W., Yang, L., Yan, X., and Wu, Y. 2011. Changes in metabolic profiles of urine from rats following chronic exposure to anticholinesterase pesticides. Pestic. Biochem. Physiol. 101: 232-239.

Yang, W., and Tiffany-Castiglioni, E. 2008. Paraquat-induced apoptosis in human neuroblastoma SH-SY5Y cells: Involvement of p53 and mitochondria. J. Toxicol. Environ. Health A 71: 289-299. 